\title{
ESTUDO DA TÉCNICA INTRACAPSULAR ASSISTIDA POR ARTROSCOPIA PARA O TRATAMENTO DA RUPTURA DO LIGAMENTO CRUZADO CRANIAL EM CADÁVERES DE CÃES
}

\author{
STUDY IN DOG'S CADAVERS OF THE ASSISTED BY ARTHROSCOPY \\ INTRACAPSULAR TECHNIQUE FOR THE TREATMENT OF THE CRANIAL \\ CRUCIATE LIGAMENT RUPTURE IN THE DOG
}

\author{
Angelica Cecilia Tatarunas ${ }^{1 *}$ ORCID - http://orcid.org/0000-0002-8478-1283 \\ Julia Maria Matera1 ORCID - http://orcid.org/0000-0001-8349-1340 \\ Maria Angelica Miglino' ORCID - http://orcid.org/0000-0003-4979-115X \\ Ana Carolina Brandão Campos Fonseca Pinto' ${ }^{1}$ ORCID - http://orcid.org/0000-0003-2833-2069 \\ Carla Aparecida Batista Lorigados ${ }^{1}$ ORCID - http://orcid.org/0000-0002-5618-7279 \\ Luanna Ferreira Fasanelo Gomes ${ }^{1}$ ORCID - http://orcid.org/0000-0002-4377-8651
}

${ }^{1}$ Universidade de São Paulo, São Paulo, SP, Brasil

*Autor para correspondência - angeltat@gmail.com

\section{Resumo}

O objetivo foi estudar e aprimorar a técnica intracapsular de reparação do ligamento cruzado cranial assistida por artroscopia em cadáveres de cães com a confecção dos túneis tibial e femoral e utilização de autoenxerto osso-tendão patelar-osso. Foram utilizados 10 membros pélvicos de cães $>20 \mathrm{~kg}$. Os túneis ósseos foram confeccionados de forma independente e na posição anatômica original dos locais de inserção do ligamento cruzado cranial. Foram realizados estudo radiográfico e tomográfico para avaliar a articulação. A coleta das porções ósseas do enxerto foi feita com osteótomo e martelo. Ocorreram fratura em três patelas e em três tuberosidades tibiais. Os enxertos apresentaram comprimento médio $7,56 \mathrm{~cm}$. Os túneis tibiais e os túneis femorais foram confeccionados no local de inserção do ligamento cruzado cranial em $80 \%$ e $90 \%$ das articulações, respectivamente. Os túneis tibiais apresentaram ângulo médio de $62,95^{\circ}$ mensurado por tomografia computadorizada. Os túneis femorais foram confeccionados em posição $13 \mathrm{hs}$ para o joelho esquerdo $(100 \%)$ e $11 \mathrm{hs}$ para o direito $(100 \%)$. Ao final do procedimento, obteve-se gaveta negativo em 100\% das articulações. Pode-se concluir que a técnica proposta é viável de ser realizada no cão, porém faz-se necessário instrumental específico devido ao pequeno tamanho da articulação canina para obter melhor acurácia.

Palavras-chave: joelho, canino, instabilidade, artroscopia.

\begin{abstract}
The aim was study and improve the intra-articular technique assisted by arthroscopy of the cranial cruciate ligament repair in dog's cadavers. The bone-patelar tendon-bone was used as a graft and were made the femoral and tibial tunnels. The hindlimb of 10 dogs cadavers weighing $>20 \mathrm{~kg}$ were harvested. The femoral and tibial tunnels were made independent of each other, in the footprint of the original cranial cruciate ligament. Radiographic and tomographic studies were performed to evaluate the joint. The osseous portions of the graft were were harversted with osteotome and hammer. Fractures occurred in 3 patellas and 3 tibial tuberosities. The medium lenght of the grafts was $7,56 \mathrm{~cm}$. Tibial and femoral tunnels were in the footprint of the cranial cruciate ligament in $80 \%$
\end{abstract}


and $90 \%$ of the joints, respectively. The tibial tunnel had an average angle of $62,95^{\circ}$ measured by computer tomography. The femoral tunnel was at $13 \mathrm{~h}$ in the left knee and at $11 \mathrm{~h}$ in the right knee in all joints (100\%). At the end of the procedure the drawer test was negative in all joints (100\%). It can be concluded that the proposed technique is feasible to be performed in the dog. But because to the small size of the canine joint it is necessary specific instruments in order to obtain better acuracy.

Keywords: stifle, canine, instability, arthroscopy.

Recebido em: 17 de julho de 2017.

Aceito em: 19 de junho de 2019.

\section{Introdução}

A ruptura do ligamento cruzado cranial ( $\mathrm{LCCr}$ ) no cão é uma doença complexa e o total entendimento de sua etiopatogenia tem desafiado os pesquisadores há décadas. Também chamada de "Doença do Cruzado", consiste, na grande maioria dos casos, na degeneração gradual deste ligamento, levando à instabilidade, doença inflamatória, ruptura parcial e, eventualmente, à ruptura total ${ }^{(1,2)}$. Uma das hipóteses é a presença de uma sinovite crônica devido à ativação de respostas imunes do ambiente articular, levando à degeneração ligamentar ${ }^{(2)}$.

A ruptura do LCCr é causa comum de claudicação e osteoartrose. O tratamento cirúrgico tem por finalidade estabilizar a articulação, aliviar a dor e, quando presente, tratar lesão concomitante de menisco ${ }^{(1)}$. Várias técnicas cirúrgicas têm sido descritas, estudadas e aplicadas para o tratamento da ruptura do LCCr no cão, porém, até os dias atuais não existe um protocolo estabelecido que restaure a cinemática normal do joelho e, consequentemente, coíba totalmente a evolução da doença articular degenerativa ${ }^{(1,3,4)}$.

Os procedimentos cirúrgicos idealizados para o tratamento desta afecção são classificados em intracapsulares, extracapsulares e osteotomias dinâmicas de neutralização ${ }^{(1,5)}$. As técnicas extracapsulares são relativamente simples. Nelas, utilizam-se um fio de sutura grosso externamente à articulação com a finalidade de coibir a instabilidade presente. As osteotomias dinâmicas (exemplo: osteotomia de nivelamento do platô da tíbia e avanço da tuberosidade da tíbia) têm por objetivo a estabilização dinâmica pela neutralização das forças que atuam na articulação ${ }^{(1,5)}$. Por outro lado, as técnicas intracapsulares consistem no restabelecimento da estabilidade articular através da substituição do ligamento rompido por outro similar, seja oriundo de tecido biológico, material sintético ou ainda uma combinação de ambos ${ }^{(1,2)}$. Estas foram as primeiras técnicas a serem utilizadas no cão, e datam de 1952, quando Paatsama utilizou a fascia lata como substituto do ligamento ${ }^{(6)}$. Outros tecidos biológicos utilizados no cão foram: tendão patelar, tendão do músculo extensor digital longo, tendões do músculo semitendíneo e grácil-hamstring e conjunto osso-tendão patelar-osso ${ }^{(6,7,8,9,10)}$.

Os estudos realizados com substituição do LCCr por autoenxerto ou mesmo material sintético no cão são carentes de padronização e realizados, em sua grande maioria, via artrotomia. A artroscopia, devido às suas características de magnificação da imagem e iluminação, promove um diagnóstico e tratamento com maior acurácia quando comparado com a artrotomia. Além disso, as técnicas cirúrgicas assistidas por artroscopia reduzem a dor pós-operatória e minimizam o tempo requerido para o retorno à função ${ }^{(11,12,13)}$.

Acredita-se que a razão pela qual as técnicas intra-articulares em cães, especialmente aquelas que 
fazem uso de túneis ósseos, falham em restaurar a cinemática normal do joelho pode estar relacionada com a escolha imprópria do enxerto e confecção incorreta na posição dos túneis ${ }^{(2,10,14)}$. Muitas variações quanto a confecção dos túneis ósseos e fixação do enxerto foram realizadas, porém sem um padrão estabelecido ${ }^{(2,6,15)}$. Em cães, atualmente, os pesquisadores têm procurado refinar e aperfeiçoar a técnica de reconstrução intracapsular do $\operatorname{LCCr}^{(2,7,14,15,16,17,18)}$. Estas sugerem que a reconstrução anatômica do enxerto do LCCr pode ser uma abordagem promissora para restaurar a estabilidade normal e cinemática articular ${ }^{(14,18)}$.

Informações publicadas confirmam a similitude no comportamento isométrico do substituto do LCCr entre joelhos caninos e humanos ${ }^{(19)}$. COOK et al. ${ }^{(20)}$ afirmam que a anatomia do joelho canino coincide com aquela do humano de forma muito próxima e a avaliação de resultados clinicamente relevantes, diagnóstico por imagem e estratégias de reabilitação, são facilmente transpostos para os cães. Consequentemente, informações obtidas de pesquisas realizadas na espécie humana fornecem um ponto de partida para investigar a reparação da ruptura do LCCr do joelho canino com a utilização de enxertos ${ }^{(15,20)}$. Portanto, esta pesquisa utiliza alguns conceitos preestabelecidos em estudos feitos no homem.

A posição dos túneis, na espécie humana, é realizada nas formas isométrica e anatômica ${ }^{(21,22,23)}$. Isometria do enxerto significa que o ligamento mantém a sua tensão durante toda a amplitude de movimento da articulação ${ }^{(21,24)}$. Atualmente, no homem, tem-se relevado a colocação do enxerto na inserção anatômica do $\mathrm{LCCr}^{(22)}$, pois tem-se definido que a isometria não existe no LCCr; não há um único ponto no fêmur que mantenha uma distância fixa de um único ponto na tíbia durante a amplitude de movimento desta articulação. Portanto, uma abordagem embasada na replicação da anatomia verdadeira, similar ao LCCr original, confeccionando os túneis ósseos o mais próximo possível de suas inserções anatômicas, tem sido priorizada ${ }^{(21,22)}$.

Ainda na espécie humana, os túneis tibial e femoral podem ser confeccionados pela técnica transtibial ou cada um de forma independente. É relatado que a técnica transtibial muitas vezes resulta em confecção não anatômica do túnel femoral ${ }^{(25)}$. O túnel femoral confeccionado de forma anatômica promove boa estabilidade rotacional e modelos de tensão e translação similares aos do LCCr original ${ }^{(24)}$. Além disso, resulta em cinemática da articulação do joelho, com maior semelhança a do joelho hígido quando comparado a um túnel isométrico ${ }^{(23)}$. A confecção errônea do túnel tibial pode causar tensão excessiva no enxerto, levando a sua falha e, consequentemente, recorrência da instabilidade articular ou à perda de tensão do enxerto, tornando-se insatisfatório em promover a estabilidade articular. Um túnel tibial confeccionado muito cranial levará à atrito do enxerto no côndilo femoral durante a extensão, comprometendo o resultado final ${ }^{(27)}$.

Em pesquisa anterior realizada em cadáveres de cães, avaliou-se a viabilidade da reconstrução do LCCr, assistido por artroscopia, utilizando-se enxerto osso-tendão patelar-osso, com confecção transtibial dos túneis ósseos e fixação com parafuso bicortical, obtendo-se resultados promissores ${ }^{(8)}$.

O presente trabalho tem por objetivo estudar em cadáveres de cães a técnica intracapsular, assistida por artroscopia, com a confecção anatômica e individual dos túneis ósseos tibial e femoral, utilizando autoenxerto de osso-tendão patelar-osso.

\section{Material e métodos}


da Universidade de São Paulo, em janeiro de 2016 a dezembro de 2017, sendo analisada e aprovada pela Comissão de Ética no Uso de Animais da referida Instituição (CEUA no 7564130215).

Foram utilizados dezmembros pélvicos de cadáveres de cães de grande porte (peso $>20 \mathrm{~kg}$ ), conservados em freezer a $-20{ }^{\circ} \mathrm{C}$ e posteriormente mantidos em temperatura ambiente para descongelamento e utilização.

O LCCr foi seccionado via artroscopia e realizada a técnica proposta. Para os túneis ósseos preconizouse a confecção anatômica, ou seja, na região de inserção original do LCCr tibial e femoral.

Foram realizados estudos de imagem radiográfico a fim de descartar prévia alteração articular que inviabilizasse o procedimento proposto e tomografia computadorizada para avaliar os resultados obtidos quanto a posição e tamanho dos túneis ósseos.

Ao final, realizou-se estudo necroscópico com o intuito de confirmar o posicionamento e dimensão dos túneis ósseos.

Fez-se incisão da pele na linha média da articulação do joelho, face cranial, cerca de $2 \mathrm{~cm}$ anteriores à patela até cerca de $3 \mathrm{~cm}$ após a crista da tíbia. Em seguida, promoveu-se a divulsão do tecido celular subcutâneo e visualização da patela, tendão patelar e crista tibial.

Inicialmente, marcou-se com lâmina de bisturi no 15 a patela, delimitando o local de incisão, que correspondeu a cerca de 1/3 de sua largura. Fez-se então a remoção desta porção óssea, com osteótomo e martelo, com a articulação flexionada. A incisão se prolongou pelo tendão patelar (1/3 da largura total) e crista tibial.

O enxerto osso-tendão patelar-osso teve suas porções ósseas aparadas com goiva até que suas dimensões se adequassem em túnel ósseo de $5 \mathrm{~mm}$ de diâmetro. Para isso, foi utilizado um medidor de diâmetro de enxerto.

Foram realizadas duas perfurações em cada uma das extremidades do enxerto, nas porções ósseas, com fio de Kirschner e furadeira. Utilizou-se fio de sutura Prolene ${ }^{\circledR}$ (Polipropileno) $n^{\circ}$ 2, o qual foi passado pelos orifícios para a posterior fixação do enxerto.

Utilizou-se artroscópio 2,7mm, o qual foi inserido através da confecção de um portal infra patelar lateral. Realizou-se a confecção de portal instrumental infra patelar medial, e com o probe fez-se inicialmente a inspeção e palpação da articulação. Com bisturi e lâmina $n^{0} 11$, fez-se a secção do LCCr, sob visualização artroscópica. Os remanescentes do ligamento foram removidos com shaver e pinças de artroscopia.

Inicialmente, procuramos identificar os pontos de referência: corno anterior do menisco lateral, eminencia intercondilar, ligamento cruzado caudal e os resquícios do LCCr na área intercondilar cranial.

Para a confecção do túnel tibial utilizou-se guia. Procurou-se posicionar uma das extremidades da guia na região de inserção do LCCr na tíbia (área intercondilar cranial), através do portal artroscópico medial e a outra extremidade da guia foi posicionada na face medial (médio proximal) da tíbia, procurando-se um ponto central. Procurou-se manter um ângulo de inclinação estimado de $60-70^{\circ}$ do túnel em relação à superfície articular. $\mathrm{O}$ túnel foi confeccionado com broca de $5 \mathrm{~mm}$.

Para a confecção do túnel femoral utilizou-se guia, o qual teve uma de suas extremidades posicionada na região de inserção do LCCr no fêmur (porção caudomedial do côndilo lateral) e na face lateral 
do côndilo femoral, cranial a fabela. Quanto a angulação, procurou-se manter a entrada do túnel em torno de $13 \mathrm{hs}$ para a articulação esquerda e em torno de $11 \mathrm{~h}$ para o joelho direito em relação a tróclea, com a articulação mantida em flexão. Foi utilizada broca $5 \mathrm{~mm}$ para a confecção do túnel.

Utilizou-se fio de aço no 1 para carrear o enxerto intra-articularmente, do túnel tibial para o femoral.

Para a fixação do enxerto, o membro foi mantido em posição anatômica, o enxerto foi tensionado e então fixado com a utilização de parafuso cortical.

Avaliou-se através do teste de gaveta a estabilidade promovida.

Foi realizada a sutura dos portais medial e lateral e sutura da pele com fio de náilon 4-0.

Foram realizadas as radiografias em projeção crânio caudal e médio lateral e o estudo de tomografia em equipamento de tomografia computadorizada helicoidal com 16 fileiras de detectores (Modelo MX8000 IDT Philips).

Em exame macroscópico das articulações, foram avaliados o local de entrada e saída dos túneis femoral e tibial, a posição do enxerto, a mensuração do comprimento do enxerto, do tendão patelar e dos túneis tibial e femoral.

\section{Resultados}

Foi realizada a secção do LCCr e posterior reparação com enxerto osso-tendão patelar-osso inserido pelos túneis ósseos tibial e femoral, confeccionados individualmente e com as suas extremidades no local de inserção do LCCr, assistido por artroscopia.

Durante a coleta dos fragmentos ósseos ocorreu fratura da patela $\left(n^{\circ} 2,3\right.$ e 8$)$ e fratura da tuberosidade da tíbia em três articulações $\left(n^{\circ} 2,6\right.$ e 8$)$.

Os enxertos apresentaram comprimento entre $7 \mathrm{~cm} \mathrm{e} 8,1 \mathrm{~cm}$ (média 7,56 cm). O fragmento patelar mediu $1 \mathrm{~cm}$ a $1,8 \mathrm{~cm}$ de comprimento (média $1,77 \mathrm{~cm}$ ); $0,2 \mathrm{~cm}$ a $0,5 \mathrm{~cm}$ de largura (média $0,34 \mathrm{~cm}$ ) e $0,2 \mathrm{~cm}$ a $0,4 \mathrm{~cm}$ de altura (média $0,3 \mathrm{~cm}$ ). $\mathrm{O}$ fragmento tibial apresentou $1 \mathrm{~cm}$ a $1,9 \mathrm{~cm}$ (média 1,56 $\mathrm{cm}$ ) de comprimento; $0,3 \mathrm{~cm}$ a $0,5 \mathrm{~cm}$ (média $0,41 \mathrm{~cm}$ ) de largura e $0,2 \mathrm{~cm}$ a $0,5 \mathrm{~cm}$ (média $0,36 \mathrm{~cm}$ ) de altura. A porção tendínea mediu $3,8 \mathrm{~cm}$ a $4,6 \mathrm{~cm}$ (média $4,38 \mathrm{~cm}$ ) de comprimento e $0,4 \mathrm{a} 0,5 \mathrm{~cm}$ (média 0,42 cm) de largura. O comprimento total do enxerto variou de 7,1 $\mathrm{cm}$ a 8,3 $\mathrm{cm}$ (média 7,56 $\mathrm{cm})$ (Quadro1).

Quanto a posição final dos fragmentos ósseos do enxerto em relação aos túneis femoral e tibial, observou-se que os fragmentos ósseos (tibial e femoral) não ficaram totalmente interiorizados nos seus respectivos túneis em nenhuma das articulações estudadas. Em três articulações, ambos os fragmentos ósseos, tibial e femoral ficaram parcialmente interiorizados em seus respectivos túneis $\left(n^{\circ} 1,3\right.$ e 6) em ambas as articulações. Em uma articulação, o fragmento ósseo ficou completamente interiorizado em um dos túneis $\left(\mathrm{n}^{\circ} 4\right)$. Em duas articulações, o fragmento ósseo ficou completamente interiorizado em um dos túneis e parcialmente interiorizado no outro túnel $\left(n^{\circ} 5,9\right)$. Em quatro articulações, o fragmento ósseo ficou parcialmente interiorizado em um túnel e exteriorizado no outro $\left(n^{\circ} 2,7,8\right.$ e 10$)$. 
Quadro 1. Dimensão do comprimento total e de cada uma das partes do enxerto (fragmento patelar, fragmento tibial e tendão patelar), comprimento do túnel tibial e do túnel femoral, obtidos por estudo necroscópico

\begin{tabular}{|c|c|c|c|c|c|c|}
\hline \multirow{2}{*}{ Art } & $\begin{array}{c}\text { Patela } \\
\mathbf{C} \mathbf{x} \mathbf{~ L ~} \mathbf{A}\end{array}$ & $\begin{array}{c}\text { Tíbia } \\
\mathbf{C} \mathbf{x} \mathbf{~ L} \mathbf{x} \text { A }\end{array}$ & $\begin{array}{c}\text { Tendão } \\
\mathbf{C} \mathbf{~} \mathbf{~ L}\end{array}$ & $\begin{array}{c}\text { Enxerto } \\
\mathbf{C} \text { Total }\end{array}$ & $\begin{array}{c}\text { Túnel Tibial } \\
\mathbf{C}\end{array}$ & $\begin{array}{c}\text { Túnel Femoral } \\
\mathbf{C}\end{array}$ \\
\hline 1 & $1,8 \times 0,3 \times 0,3$ & $1,5 \times 0,3 \times 0,2$ & $3,8 \times 0,4$ & 7,1 & 2,2 & 2,5 \\
\hline 2 & $2 \times 0,3 \times 0,3$ & $1,5 \times 0,3 \times 0,4$ & $4,5 \times 0,5$ & 8 & 1,6 & 2,2 \\
\hline 3 & $1 \times 0,4 \times 0,3$ & $1,5 \times 0,3 \times 0,3$ & $4,5 \times 0,4$ & 7 & 1,2 & 2,3 \\
\hline 4 & $1,5 \times 0,5 \times 0,3$ & $1 \times 0,5 \times 0,3$ & $4,5 \times 0,4$ & 7 & 2,1 & 1,6 \\
\hline 5 & $1,5 \times 0,2 \times 0,3$ & $1,7 \times 0,4 \times 0,4$ & $4,5 \times 0,4$ & 7,7 & 1,8 & 2,4 \\
\hline 6 & $1,8 \times 0,3 \times 0,2$ & $2 \times 0,4 \times 0,4$ & $4,5 \times 0,4$ & 8,3 & 2 & 2,2 \\
\hline 7 & $1,6 \times 0,4 \times 0,4$ & $1,7 \times 0,5 \times 0,4$ & $4,5 \times 0,4$ & 7,8 & 1,8 & 2,1 \\
\hline 8 & $1,8 \times 0,3 \times 0,2$ & $1,3 \times 0,4 \times 0,5$ & $4 \times 0,4$ & 7,1 & 2,8 & 1,8 \\
\hline 9 & $1,6 \times 0,3 \times 0,3$ & $1,5 \times 0,5 \times 0,3$ & $4,4 \times 0,4$ & 7,5 & 2,4 & 2,1 \\
\hline 10 & $1,6 \times 0,4 \times 0,4$ & $1,9 \times 0,5 \times 0,4$ & $4,6 \times 0,5$ & 8,1 & 2 & 2 \\
\hline$M$ & $1,77 \times 0,3 \times 0,3$ & $1,6 \times 0,4 \times 0,4$ & $4,4 \times 0,4$ & 7,56 & 2,02 & 2,12 \\
\hline
\end{tabular}

C: Comprimento; L: Largura; A: Altura

Os portais artroscópico e instrumental foram realizados em posição infrapatelar lateral e medial, respectivamente, e foram satisfatórios para a realização da técnica cirúrgica proposta.

Em todas as articulações estudadas foi necessária a realização da remoção extensa da gordura infra patelar e dos resquícios de LCCr nos seus locais de inserção na tíbia e no fêmur com shaver e pinças de artroscopia para a visualização das estruturas anatômicas de interesse e realização da técnica cirúrgica proposta.

O comprimento do túnel tibial variou de 1,2 a 2,8cm (média 2,02cm).

A posição do orifício no platô tibial foi na área intercondilar cranial conforme estabelecido em 8 articulações. Em uma articulação foi confeccionado caudal e em outra cranial ao local proposto.

A posição do orifício na face medial da tíbia apresentou distância entre 0,5 a 1,6cm (média $1,03 \mathrm{~cm}$ ) em relação a superfície articular. O comprimento do túnel femoral variou de 1,6 a 2,5cm (média $2,12 \mathrm{~cm})$.

A posição do orifício intra-articular do túnel femoral foi na região caudomedial do côndilo lateral do fêmur, no local de inserção do LCCr em nove articulações. Em uma articulação, o orifício esteve cranial ao local proposto. A distância do orifício extra-articular do túnel femoral em relação ao ponto de inserção do tendão do extensor digital longo variou de 0,2 a $1,5 \mathrm{~cm}$ (média: $0,88 \mathrm{~cm}$ ).

A passagem do enxerto foi realizada via artroscopia com auxílio de fio de aço como guia, sendo carreado do túnel tibial para o femoral. Durante a passagem ocorreu resistência na entrada do túnel femoral em três articulações. Em duas articulações houve o rompimento do orifício que mantinha o fio à porção óssea do enxerto. Nestas articulações, houve a necessidade de fixar o fio à porção tendínea do enxerto.

Em todas as articulações, obteve-se gaveta negativa, com estabilidade satisfatória ao fim do procedimento. 
Através do exame radiográfico, observou-se ausência de doença articular degenerativa ou outro tipo de alteração que inviabilizasse a realização do procedimento. Os ângulos dos túneis tibiais e femorais foram mensurados nos exames tomográficos (Figura 1).

Os túneis femorais apresentaram ângulo que variou entre $49,44^{\circ}$ a $82,2^{\circ}$, sendo a média $62,95^{\circ}$. No túnel femoral, observou-se que todos os joelhos esquerdos tinham o túnel femoral em posição em torno de $13 \mathrm{~h}$ e os joelhos direitos em posição em torno de 11h (Quadro 2).
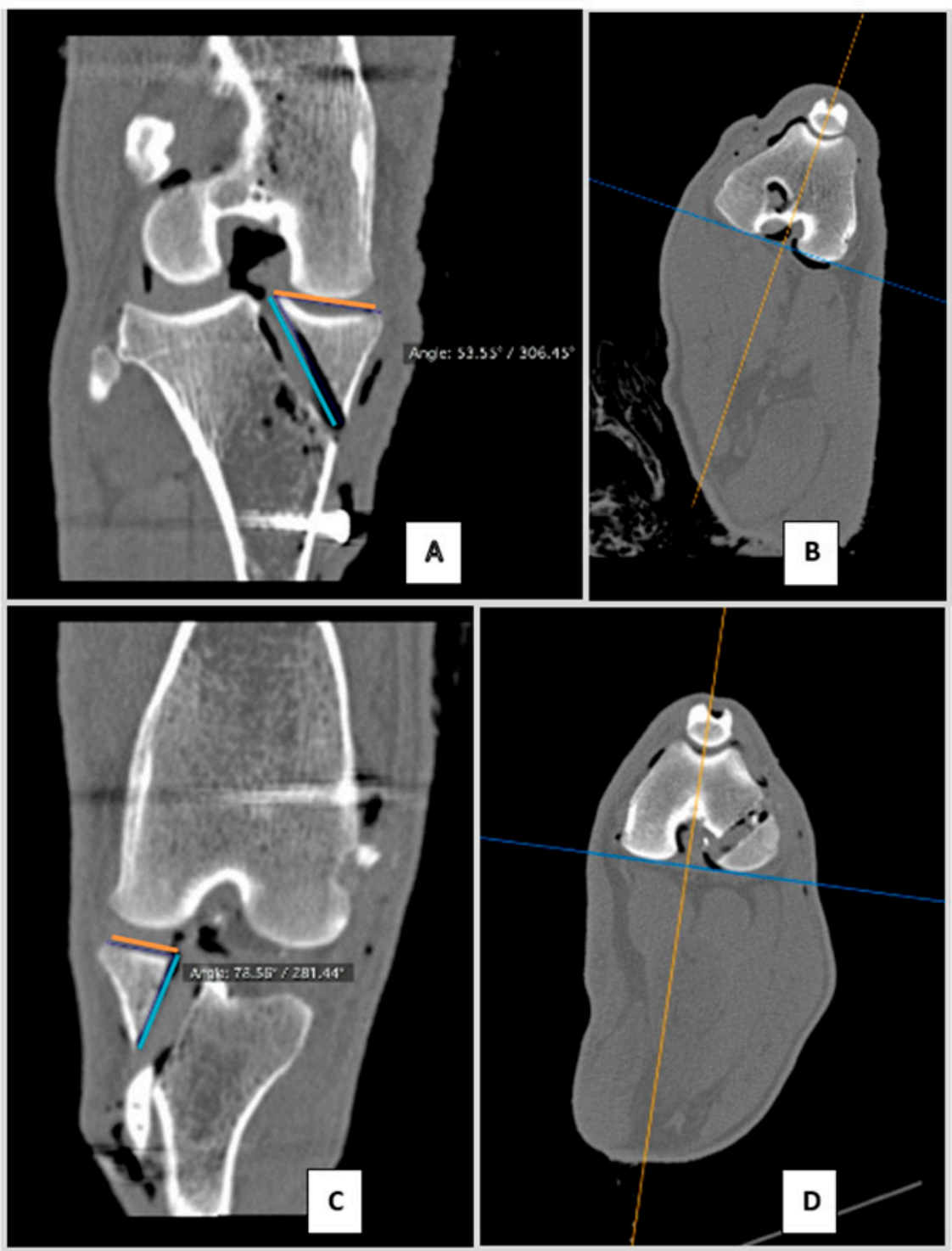

Figura 1. Imagens por tomografia computadorizada das articulações fêmuro-tíbio patelares direita e esquerda, em planos transversal e frontal. Nas imagens A e C, demonstra-se a mensuração do ângulo do túnel tibial em relação ao platô da tíbia. Nas imagens B e D, demonstra-se a localização dos túneis femorais nas posições $11 \mathrm{hs}$ e $13 \mathrm{hs}$. 
Quadro 2 - Ângulos do túnel tibial (graus) e posição do túnel femoral (horas), mensurados em imagens de tomografia computadorizada

\begin{tabular}{|c|c|c|}
\hline Articulação & Túnel Tibial & Túnel Femoral \\
\hline 1 & $71,64^{\circ}$ & 13 horas \\
\hline 2 & $60,02^{\circ}$ & 11 horas \\
\hline 3 & $53,55^{\circ}$ & 11 horas \\
\hline 4 & $73,49^{\circ}$ & 13 horas \\
\hline 5 & $47,31^{\circ}$ & 11 horas \\
\hline 6 & $78,56^{\circ}$ & 13 horas \\
\hline 7 & $49,44^{\circ}$ & 11 horas \\
\hline 8 & 82,20 & 13 horas \\
\hline 9 & $47,70^{\circ}$ & 11 horas \\
\hline 10 & $65,57^{\circ}$ & 13 horas \\
\hline Média & $62,95^{\circ}$ & - \\
\hline
\end{tabular}

\section{Discussão}

No cão, o uso de enxertos para a reparação intracapsular do LCCr rompido tem sido foco de estudo de pesquisadores nos últimos anos ${ }^{(2,7,8,14,15,16,17,18)}$. Apesar de ter sido a primeira técnica a ser empregada para tratar esta doença e ter sido utilizada por muitas décadas na espécie canina, ainda carece de informações. Enquanto no homem existem dados concretos a respeito da confecção da técnica e os procedimentos são todos realizados via artroscopia, no cão a artrotomia ainda é de eleição e a informação técnica extremamente deficitária.

Em cães, atribui-se a ruptura do LCCr, ou também chamada de Doença do Cruzado, a progressiva degeneração deste ligamento até a sua ruptura, sendo que a causa não é completamente elucidada ${ }^{(1,2)}$. Apesar de existir a hipótese de que nas reconstruções intracapsulares o ligamento ficaria suscetível a este ambiente modificado, o estudo e aprimoramento desta técnica em cães é importante, pois nos últimos anos vários materiais vêm sendo desenvolvidos como substituto do ligamento, quer sejam sintéticos ou na área de engenharia tecidual ${ }^{(2,3,5)}$.

No presente trabalho, procurou-se estudar em cadáveres de cães a técnica intracapsular para a reparação do LCCr, assistida por artroscopia, utilizando-se o enxerto osso-tendão-patelar-osso; e, dando-se especial atenção à confecção e localização dos túneis ósseos. O joelho canino é somente metade a um terço do tamanho de um joelho humano ${ }^{(17)}$, o que torna a cirurgia artroscópica nesta espécie exigente em termos de equipamento e destreza com procedimento minimamente invasivo.

Pesquisas realizadas em cães para a reparação do LCCr através de técnica intracapsular, assistido por artroscopia, são escassos na literatura ${ }^{(14,17)}$. Neste estudo, utilizamos para a abordagem da articulação os portais infrapatelar lateral para o artroscópio, infrapatelar medial para o instrumental e suprapatelar medial com cânula fenestrada para o portal de drenagem, sendo satisfatórios para o procedimento proposto.

Para a confecção da técnica cirúrgica, foi necessária a adaptação e criação de instrumentais similares 
ao que é utilizado no homem. Tais instrumentais, mais específicos e refinados, não são disponíveis no mercado para a espécie canina. Idealizamos o desenho de um medidor de diâmetro de enxerto e solicitamos a sua confecção. Este mostrou-se adequado para o objetivo proposto.

Winkels et al. ${ }^{(14)}$ e Bolia; Böttcher ${ }^{(17)}$ desenvolveram e testaram in vitro uma guia para a confecção do túnel tibial e femoral, respectivamente, no cão. As guias são imprescindíveis para a confecção dos túneis ósseos quando realizamos a reparação intra-articular do LCCr assistida por artroscopia ${ }^{(17)}$. Neste estudo, utilizamos C-guia, disponível no mercado de instrumentos ortopédicos veterinários. Este tipo de guia é de fácil aquisição e custo relativamente baixo, porém diferente das guias utilizadas no homem para a reparação do LCCr, não permitem estimar o ângulo do túnel a ser confeccionado. Em verdade, este detalhe ainda parece estar longe de ser determinado para a articulação canina. Atualmente, a principal preocupação dos pesquisadores é determinar a localização dos pontos de entrada dos túneis ósseos na articulação.

Segundo Clark et al. ${ }^{(26)}$, um enxerto ideal de $\mathrm{LCCr}$ deveria usar material forte o suficiente para substituir o ligamento, ter mínima morbidade no local de coleta, possuir colocação e fixação acurada, permitir imediata sustentação de peso e plena amplitude de movimento.

Os autoenxertos utilizados em cães para a reconstrução do LCCr são o tendão patelar, fáscia lata e os tendões semitendinoso e grácil - hamstring ${ }^{(2,7,8,9,14)}$. No homem, o enxerto osso-tendão patelarosso, proveniente do terço central do tendão patelar, juntamente com o hamstring, são os tecidos mais utilizados ${ }^{(21)}$. Um enxerto de osso-tendão patelar-osso no homem corresponde a $120 \%$ da força do LCCr normal e reobtém mais de $80 \%$ da força original do ligamento durante um período de seis $\operatorname{meses}^{(27)}$.

Foram realizados estudos experimentais em cães avaliando a pressão no contato patelofemoral após a remoção do terço central e do terço lateral ou medial do enxerto osso-tendão patelar-osso ${ }^{(28,29)}$, concluindo-se que, enquanto a remoção do terço central não promoveu alterações significativas, houve modificação na soma dos vetores do músculo quadríceps após a remoção tanto do terço medial como do terço lateral do tendão patelar, apesar do fato de a coleta destas porções ser simplificada e criar menos trauma no leito doador quando comparado com a remoção do terço central ${ }^{(30)}$.

No presente estudo, optamos pela remoção do terço central do tendão patelar, pois as pesquisas acima suportam o seu uso quanto a biomecânica como autoenxerto para a reconstrução do LCCr no cão. Durante a coleta do enxerto, houve a fratura em três $(30 \%)$ patelas e em três $(30 \%)$ tuberosidades da tíbia, o que foi creditado ao modo de coleta com o uso de osteótomo e martelo. Segundo Shrock; Jackson $^{(31)}$, no homem tem-se preferência pela serra oscilante ao invés do osteótomo e martelo, pois diminui o trauma para a superfície articular, promove maior facilidade e rapidez de coleta e permite a obtenção de um fragmento semicilíndrico uniforme. Um dos desafios da articulação canina para a realização da reparação do LCCr com o uso do enxerto osso-tendão patelar-osso assistido por artroscopia tal qual é realizado no homem é o pequeno tamanho da articulação. Portanto, acredita-se que a utilização da serra na articulação canina para a coleta dos fragmentos ósseos provavelmente corroboraria com as vantagens descritas por Shrock; Jackson ${ }^{(31)}$. Acrescentamos ainda que a coleta dos fragmentos ósseos em padrão uniforme provavelmente facilitaria a realização dos orifícios para a passagem do fio de fixação do enxerto, pois em duas articulações houve a falha com ruptura destes orifícios durante a tração do enxerto para a sua passagem pelos túneis ósseos. Tal fato foi creditado a irregularidade e pequena dimensão destes fragmentos ósseos, principalmente no que tange à medida de sua profundidade (altura), porém observou-se também que é imperativo a completa remoção dos resquícios do LCCr da articulação, pois isto facilita a entrada e posterior passagem do fragmento ósseo através do túnel (femoral). 
A utilização do enxerto osso-tendão patelar-osso apresenta como uma de suas vantagens a cicatrização osso (enxerto) e osso (leito receptor), a qual ocorre em menor tempo quando comparada com a cicatrização tendão e osso, favorecendo a realização de uma reabilitação mais intensa e precoce descrita no homem ${ }^{(32)}$. Nesta pesquisa, observamos que os fragmentos ósseos do enxerto (tibial e femoral) não ficaram totalmente interiorizados nos seus respectivos túneis em nenhuma das articulações estudadas. Existiu, nos cadáveres, uma discordância na relação do comprimento total do enxerto com o comprimento dos túneis ósseos somado à porção intra-articular. Portanto, faz-se necessário reavaliar, na espécie canina, a possibilidade de confecção de túneis mais longos para se obter o contato osso com osso durante a cicatrização do enxerto. Para isso, sugerimos que seja utilizado outro formato de guia, preferencialmente com a possibilidade de predeterminar o comprimento e o ângulo dos túneis ósseos.

Para a confecção dos túneis ósseos, são utilizadas a técnica transtibial, na qual o túnel femoral é confeccionado em continuidade e a partir do túnel tibial; ou, ambos os túneis são confeccionados independentemente. A técnica transtibial, por sua vez, promove maior restrição para a escolha de posição e direção do túnel femoral ${ }^{(25)}$. Em estudo anterior em cadáveres de cães utilizando o enxerto osso-tendão patelar-osso, realizamos a técnica transtibial para a confecção do túnel femoral ${ }^{(8,19)}$. Porém, nesta pesquisa, optamos por utilizar o portal infrapatelar medial para a confecção independente do túnel femoral e concordamos com os autores acima sobre a melhor possibilidade de direcionar o túnel no seu ponto anatômico, quando comparado a transtibial. Sugere-se, portanto, no cão, a realização independente dos túneis ósseos nos locais de inserção anatômica original deste ligamento.

De acordo com Ryan et al. ${ }^{(21)}$, a isometria do LCCr não existe, pois não existe nenhum ponto específico no fêmur que mantenha uma distância fixa a um outro ponto específico na tíbia durante a amplitude de movimento do joelho. O LCCr é constituído por duas bandas e enquanto a banda anteromedial fica tensa durante a flexão e frouxa na extensão, a banda posterolateral experiencia maior estresse durante a extensão. Portanto, apesar da preocupação e grande número de estudos no homem sobre a isometria do enxerto na reconstrução do LCCr, tem-se observado que atualmente este não é o fator primordial na reconstrução do ligamento, mas sim a "isometria" pela colocação do enxerto na inserção anatômica nativa do LCCr.

Segundo Hinderhaug et al. ${ }^{(33)}$, na proposta anatômica para a reconstrução do LCCr na articulação do homem, a confecção dos túneis ósseos baseia-se em pontos de referência, os quais podem apresentar variação quanto a presença e visibilidade, tornando a sua identificação por artroscopia desafiante ao cirurgião. Neste estudo, nos baseamos principalmente na localização dos resquícios de ligamento presentes no aspecto caudo-medial do côndilo femoral lateral e na superfície da tíbia, para a confecção dos túneis femoral e tibial, respectivamente. Concordamos com Whitney e Bolia; Bottcher, ${ }^{(13,17)}$ que na articulação do cão é necessário debridar quase que completamente os resquícios de ligamento para visualização dos pontos anatômicos. Durante o estudo necroscópico, observamos que em nove articulações $(90 \%)$ o orifício de entrada do túnel ósseo femoral encontrava-se no local almejado, e em uma articulação tal orifício encontrava-se cranial ao local de inserção do ligamento. Quanto à tíbia, em oito (80\%) articulações o orifício de entrada do túnel encontrava-se no local de inserção do LCCr; e em uma articulação, este encontrava-se caudal; e em outra, cranial ao local desejado. Acreditamos que a carência de instrumental e equipamento mais refinado para a realização da técnica via artroscopia na pequena articulação do cão corroboraram para esta pequena porcentagem de desvio na posição dos túneis ósseos em relação ao local almejado.

A artroscopia é um método de avaliar e tratar estruturas intra-articulares do joelho com mínima morbidade e extrema precisão ${ }^{(11,12,13)}$, pois associa magnificação da imagem e iluminação. Acreditamos que a técnica realizada assistida por artroscopia permite acurácia na confecção dos túneis ósseos tal 
qual é obtida no homem ${ }^{(27)}$, mas há a necessidade de material específico para a articulação canina como guias para a confecção dos túneis, além de longa curva de aprendizado.

A correta confecção dos túneis ósseos é fator imprescindível para o sucesso do procedimento cirúrgico. É relatado que no homem a confecção do túnel femoral em posição anterior à estabelecida pode levar a restrição da flexão no joelho e tensão do enxerto durante a flexão. Também, a confecção do túnel tibial em posição anterior à estabelecida pode levar a atrito do enxerto na margem troclear, com consequente falha do enxerto(21,25). Estas alterações ainda não foram estudadas e descritas na articulação canina.

No homem, preconiza-se um ângulo de $50^{\circ}$ a $70^{\circ}$ para o túnel tibial e uma posição de 11 hs e 13 hs para o joelho esquerdo e direito em relação a tróclea, respectivamente, para o túnel femoral. Não existe um valor determinado para a espécie canina e, portanto, nos baseamos nos valores utilizados no homem. Obtivemos um valor médio para o túnel femoral de $62,95^{\circ}$, estando próximo ao proposto. Os valores destes ângulos precisam ser melhores determinados para a espécie canina. Cook et al. ${ }^{(18)}$ realizaram estudo experimental em que promovem a reparação da banda craniomedial do LCCr, após sua secção, assistido por artroscopia. Mantiveram a banda caudolateral intacta. Descrevem a realização dos túneis femoral e tibial tendo o local de inserção anatômico do ligamento como referência e descrevem um ângulo de $70^{\circ}$ para o túnel tibial. Os dados utilizados no presente estudo assemelham-se e concordam em parte com os autores acima.

\section{Conclusões}

Através do presente estudo pudemos concluir que a técnica intracapsular utilizando o enxerto ossotendão patelar-osso é viável de ser realizada no cão, utilizando-se como referência para a confecção dos túneis femorais o local de inserção anatômica do LCCr na tíbia e no fêmur, porém as porções ósseas dos enxertos não ficaram interiorizadas nos túneis ósseos como desejado.

Os portais artroscópicos utilizados, infrapatelar medial e infrapatelar lateral, foram satisfatórios para a realização do procedimento.

Instrumentais específicos são necessários para a realização do procedimento, tal como guia e medidor de enxerto.

A coleta do enxerto osso-tendão patelar-osso com o uso de osteótomo e martelo tem grande potencial para promover fratura de patela ou de tuberosidade da tíbia.

\section{Agradecimentos}

CAPES (Bolsa de Pós-Doutorado)

Mauricio Testa - Monge Ryozan (auxilio na confecção do medidor de enxerto)

\section{Referências}

1. Kowaleski MP, Boudrieau RJ, Pozzi A. Stifle Joint. In: Tobias KM, Johnston SA. Veterinary Surgery Small 
Animal. St.Louis: Saunders; 2012. p. 906-98.

2. Manley PA. Intra-articular stabilization. In: Muir P. Advances in the canine cranial cruciate ligament. Iowa:Wiley-Blackwell; 2010.p.189-94.

3. Molsa SH, Hyytiainen HK, Hielm-Bjorkman AK, Laitinen-Vapaavuori OM. Long-term functional outcome after surgical repair of cranial cruciate ligament disease in dogs. BMC Vet Res. 2014 Nov 19(10):266-77. doi: 10.1186/s12917-014-0266-8.

4. Conzemius MG, Evans RB, Besancon MF. Effect of surgical technique on limb function after surgery for rupture of the cranial cruciate ligament in dogs. J Am Vet Med Assoc. 2005 Jan 15;226(2):232-6.

5. Gibson T. Evidence for a superior surgical method for treatment of canine cruciate rupture: is there any? In: Proceedings of the ACVS Surgery Summit American College of Veterinary Surgeons; October 22-24; Nashville, Tennessee, 2015, 704-5

6. Burnett QM, Fowler P.J. Reconstruction of the anterior cruciate: Historical review. Orthop Clin N Am. 1985 Jan;16(1):143-57.

7. Biskup J, Balogh D, Haynes K, Freeman A, Conzemius MG. Mechanical properties of four allograft reconstruction techniques for ruptured cranial cruciate ligament in the dog. In: Proceedings of the 42nd Annual Veterinary Orthopedic Society Conference; February 28 - March 7, 2015; Sun Valley, Idaho, 2015, 65.

8. Matera JM, Albuquerque RFM, Tatarunas AC, Sasaki SU, Prada FS Arthroscopically assisted reconstruction of the cranial cruciate ligament in dogs cadavers using the bone-patellar tendon-bone graft. Proceedings of the 2nd World Veterinary Orthopedic Congress and 33rd Annual VOS Meeting, February 25 - March, 4; Keystone, Colorado, 2006. 71-72.

9. Lopez MJ, Markel MD Kalscheur V, Lu Y, Manley PA. Hamstring graft technique for stabilization of canine cranial cruciate ligament deficient stifles. Vet Surg. 2003 Jul-Aug;32(4):390-401.

10. Arnoczky SP, Tarvin GB, Marshall JL. Anterior cruciate ligament replacement using patellar tendon. An evaluation of graft revascularization in the dog. J Bone Joint Surg Am. 1982 Feb;64(2):217-24.

11. Pozzi A, Hildreth BE, Rajala-Schulz PJ. Comparison of arthroscopy and arthrotomy for diagnosis of medial meniscal pathology: An ex vivo study. Vet Surg. 2008 Dec;37(8):749-55. doi: 10.1111/j.1532950X.2008.00442.X.

12. Hoelzler MG, Millis DM, Francis DA. Results of arthroscopic versus open arthrotomy for surgical management of cranial cruciate ligament deficiency in dogs. Vet Surg. 2004 Mar-Apr;33(2):146-53. doi: 10.1111/j.1532-950X.2004.04022.X

13. Whitney W.O. Arthroscopically assisted surgery of the stifle joint. In: Beale BS, Hulse DA, Schulz KS, Whitney WO. Small Animal Arthroscopy. Philadelphia: Saunders; 2003. p. 117-57.

14. Winkels P, Werner H, Grevel V, Oechtering B, Böt tcher P. Development and in situ application of an adjustable aiming device to guide extra- to intraarticular tibial tunnel drilling for the insertion of the cranial cruciate ligament in dogs. Vet Surg. 2010 Apr;39(n):324-33. doi: 10.1111/j.1532-950X.2010.00652.x.

15. Ho-Eckart LK, Seki M, Luizza LM, Kearney MT, Lopez MJ. Joint stability after canine cranial cruciate ligament graft reconstruction varies among femoral fixation sites. Vet Surg. 2017 Feb;46(2):213-225. doi: $\underline{10.1111 / v s u .12609 .}$.

16. Barnhart MD, Maritato K, Schankereli K, Wotton H, Naber S. Evaluation of an intra-articular synthetic ligament for treatment of cranial cruciate ligament disease in dogs: a six-month prospective clinical trial. Vet Comp Orthop Traumatol. 2016 Nov;23;29(6):491-8. Doi:10.3415/VCOT-15-12-0206. 
17. Bolia A, Botcher P. Arthroscopic assisted femoral tunnel drilling for the intra-articular anatomic cranial cruciate ligament reconstruction in dogs. Tierarztl Prax Ausg K Kleintiere Heimtiere. 2015;43(5):299-308. doi: $\underline{10.15654 / \mathrm{TPK}-141128 .}$.

18. Cook JL, Smith PA, Stannard JP, Pfeiffer FM, Kuroki K, Bozynski CC, Cook CR. A canine hybrid double bundle model for study of arthroscopic ACL reconstruction. 2016 Jun;32(6):1086-1097. doi: 10.1016/j. arthro.2015.11.026.

19. Palmisano MP, Andrish JT, Olmstead ML. A comparative study of the length pattern of the anterior cruciate ligament reconstruction in dog and man. Vet Comp Orthop Traumatol. 2000;13(1):73-77.

20. Cook JL, Hung CT, Kuroki K, Stoker AM, Cook CR, Pfeiffer FM, Sherman S.L, Stannard JP. Animal models of cartilage repair. Bone Joint Res. 2014 Apr 2;3(4):89-94. doi: 10.1302/2046-3758.34.2000238.

21. Ryan F, Nanjayan SK, Quah C, Ramoutar D, Konan S, Haddad FS. Review of evolution of tunnel position in anterior cruciate ligament reconstruction. World J Orthop. 2015 Mar 18,6(2):252-62. doi:10.5312/wjo. $\underline{v 6 . i 2.252}$

22. Garofalo R, Moretti B, Kombot C, Moretti L, Mouhsine E. Femoral tunnel placement in anterior cruciate ligament reconstruction rationale of the two incision technique. J Orthop Surg Res. 2007 May;21(2):10. doi:10.1186/1749-799X-2-10

23. Musahl V, Plakseychuk A, Vanscyoc A, Sasaki T, Debski RE, McMahon PJ, Fu FH. Varying femoral tunnels between the anatomical footprint and isometric positions: effects on kinematics of the anterior cruciate ligament reconstructed knee. Am J Sports Med. 2005 May;33(5):712-8. doi:10.1177/0363546504271747

24. Zavras TD, Race A, Amis AA. The effect of femoral attachment location on anterior cruciate ligament reconstruction: graft tension patterns and restoration of normal anterior posterior laxity patterns. Knee Surg Sports Traumatol Arthrosc. 2005 Mar;13(2):92-100. Doi:10.1007/s00167-004-0541-5

25. Strauss EJ, Barker JU, Mcgill K, Cole BJ, Bach BR, Verma NN. Can anatomic femoral tunnel placement be achieved using a transtibial technique for hamstring anterior cruciate ligament reconstruction? Am J Sports Med. 2011 Jun;39(6):1263-9. doi: 10.1177/0363546510395488.

26. Clark R, Olsen RE, Larson BJ, Goble EM, Farrer RP. Cross-pin femoral fixation: Q new technique for hamstring anterior cruciate ligament reconstruction of the knee. Arthroscopy. 1998 Apr; 14(3):258-67.

27. Phillips B. Lesões do ligamento cruzado anterior. In: Andrews JR, Timmerman LA. Artroscopia Diganóstico e Cirurgia. Rio de Janeiro: Revinter, 2000, 349-84.

28. Chan KM, Qin L, Li CK, Hung LK, Tang CY, Rolf C. Alteration of patellofemoral contact during healing of canine patellar tendon after removal of its central third. J Biomech. 2000 Nov;33(11):1441-51.

29. Chan KM, Qin L, Li CK, Hung LK, Tang CY, Rolf C. Removal of the lateral or medial third of patellar tendon alters the patellofemoral contact pressure and area: an in vitro experimental study in dogs. Clin Biomech. 2000 Nov;15(9):695-701.

30. Heegaard J, Leyvraz PF, Curnier A, Rakotomanana L, Huiskes R. The biomechanics of the human patella during passive knee flexion. J Biomech. 1995 Nov;28(11):1265-79.

31. Shrock KB, Jackson DW. Arthroscopic management of the anterior cruciate ligament-deficient knee In: Mc Ginty JB, Caspari RB, Jackson RW, Poehling GG. Operative Arthroscopy, 2. ed. Lippincott-Raven Publishers, Philadelphia, 1996, Chapter 34, p. 511-530.

32. Tomita F, Yasuda K, Mikami S, Sakai T, Yamazaki S, Tohyama H. Comparisons of intraosseous graft healing between the doubled flexor tendon graft and the bone-patellar tendon-bone graft in anterior cruciate ligament 
reconstruction. Arthrosc: J Arthrosc Relat Surg. 2001 May;17(5):461-76. doi:10.1053/jars.2001.24059.

33. Hinderhaug E, Larsen A, Waaler PA, Strand T, Harlem T, Solheim E. The effect of intraoperative fluoroscopy on the accuracy of femoral tunnel placement in single-bundle anatomic ACL reconstruction. Knee Surg Sports Traumatol Arthrosc. 2017 Apr;25(4):1211-18. doi: 10.1007/s00167-015-3858-3. 